\title{
Survival of Patients with Floor of Mouth Squamous Cell Carcinoma Treated with Surgical Resection and Reconstruction
}

SADJ October 2021, Vol. 76 No. 9 p537 - p544

N Thokan', S Maharaj²

\begin{abstract}
\section{Background}

To identify predictors of survival in patients with floor of mouth Squamous Cell Carcinoma (FOMSCC) in order to improve patient selection for resource intensive resection and reconstruction procedures.
\end{abstract}

\section{Methods \\ A retrospective record review of patients who underwent resection and reconstruction for FOMSCC at Charlotte Maxeke Johannesburg Academic Hospital. Patient data were collected and analyzed with respect to age, sex, race, tobacco usage, alcohol usage, tumour stage and postop- erative chemo-radiation. One- and five-year recurrence and survival rates were also evaluated.}

\section{Results}

Within the study period, 20 patients were identified that were treated with resection and reconstruction for FOMSCC. The mean age at diagnosis was 56.85 years, with 70 percent of the sample being male and fifty percent being black. Amongst the sample, 90 percent of patients used tobacco and 60 percent were frequent alcohol users. The most common stage at diagnosis was stage IVA which was found in 40 percent of the sample.

There were no significant factors associated with recurrence at 1 year. At 5 years, alcohol usage was a significant predictor of recurrence $(P=0.044)$.

There were no significant factors associated with death at 1 year however tumour stage at 5 years was a significant predictor $(\mathrm{P}=0.035)$.

\section{Author affiliations:}

1. N Thokan: Department of Neurosciences, Yale Road, Parktown

2. University of the Witwatersrand, Johannesburg, Gauteng, South Africa.

3. Prof. Shivesh Maharaj: MBBCH,MMED,FCORL, Department of Neurosciences , Yale Road, Parktown.

Orcid number 0000-0002-2118-2400

\section{Corresponding authors:}

Dr SH Maharaj: (University of the Witwatersrand, Johannesburg), Email: Shivesh.maharaj@wits.ac.za, Tel: 0114884299

\section{Author contributions:}

1. Nishat Thokan: Main author and writer

2. Shivesh Maharaj: Concept and editing
Out of 20 patients, five patients had recurrence. Total person-time was 72.9 person-years, with a mean follow-up time of 3.65 (SD 2.04) years per person. Out of 20 patients, nine patients died within 5 years (45\%). Alcohol was the only statistically significant factor associated with increased mortality

\section{Conclusion}

Our findings suggest earlier diagnosis, and active treatment of early stage disease may be the best means of improving 5 -year survival rates. Efforts to improve quality of care and manage limited resources should concentrate on choosing the appropriate disease stage for surgical management, improve cancer surveillance and strengthen referral system so as to improve early detection of disease and provide social support and counselling for adjunctive habits such as alcohol and tobacco use cessation which will improve patient outcomes.

\section{Keywords}

Floor of mouth squamous cell carcinoma. Survival, Recurrence

\section{INTRODUCTION}

Oral cavity malignancies are the eighth most common cancer worldwide. ${ }^{1}$ Floor of mouth malignancies are the second most common sub-site in the oral cavity after tongue malignancies. ${ }^{2,3}$ Globally $95 \%$ of oral cavity malignancies are squamous cell carcinoma (SCC) ${ }^{2,4}$

The floor of mouth is defined as the mucosal surface below the tongue bordered by the alveolar ridge laterally and anteriorly, and the oral tongue posteriorly and medially. ${ }^{5}$ The lingual frenulum divides it in the midline. Its deep margin is the mylohyoid muscle. The contents include the sublingual glands, the deep portion of the submandibular gland, the sub-epithelial minor salivary glands, the deep lingual vessels, Wharton's duct and the lingual nerve..$^{5}$ The arterial supply to the floor of the mouth is from the dorsal lingual, sublingual, and deep lingual branches of the lingual artery. The venous drainage is via the lingual veins that drain into the facial and retromandibular veins. ${ }^{5}$ The lingual nerve provides general sensory innervation to the floor of the mouth and tongue as well as special taste sensation through the accompanying chorda tympani branch of the facial nerve.5 Primary neoplasms may arise from the mucosa, salivary glands, muscle or neurovascular tissues. ${ }^{5}$ 
Table I: Overall characteristics of patients with FOMSCC

\begin{tabular}{ll}
\hline Variable & $\mathrm{N}(\%)$ \\
\hline Demographics & \\
Age, mean (standard deviation) & \\
Gender & $14(70.0)$ \\
Male & $6(30.0)$ \\
Female & \\
Race & $10(50.0)$ \\
Black & $8(40.0)$ \\
White & $2(10.0)$ \\
Coloured & \\
\hline Risk Factors & $18(90.0)$ \\
Tobacco users & $12(60.0)$ \\
Alcohol users & \\
Clinical findings & \\
Stage at diagnosis & $3(15.0)$ \\
Stage I & $3(15.0)$ \\
Stage II & $6(30.0)$ \\
Stage III & $8(40.0)$ \\
Stage IVA & \\
Treatment & $14(70.0)$ \\
Chemo-radiation received & \\
Outcomes & $1(5.0)$ \\
Recurrence at 1 year & $5(25.0)$ \\
Recurrence at 5 years & $2(10.0)$ \\
Death by 1 year & $9(45.0)$ \\
\hline Death by 5 years & \\
\hline
\end{tabular}

Lymphatic drainage of the floor of mouth is via the cervical lymph nodes. The first echelon lymph nodes of the floor of mouth are located in the supra-omohyoid triangle. ${ }^{6}$ The lymphatic channels accompany the lingual venous system, and their density increases from the anterior to the posterior. Lymphatic metastases generally occur in a predictable fashion, but skip lesions may be noted. ${ }^{2}$

Risk factors known for development of oral SCC (OSCC) are tobacco usage, alcohol consumption, nutritional deficits (carotenoids \& vitamin A, C and E), Fanconi's anaemia, a genetic predisposition, Human Papilloma Virus infection, previous head and neck malignancy and radiation exposure. Betel quid chewing (made of the areca nut wrapped in betel leaf) amongst the Asian population is also known to be a strong risk factor. ${ }^{5}$

Premalignant lesions which represent varying degrees of epithelial dysplasia are also a significant risk factor for oncogenesis. The most common premalignant lesions in the oral cavity are leukoplakia, erythroplakia, and submucous fibrosis. $^{5}$

The Tumour, Node, Metastases (TNM) staging system devised by the American Joint Committee of Cancer (AJCC) is used to categorize malignancies of the oral cavity (Appendix 1). The staging assists with assessment of disease status, prognosis and management. ${ }^{7}$ All available clinical findings may be used in staging including physical exam, radiologic, intraoperative, histopathology and biomarkers. ${ }^{8}$ Stage of disease at time of treatment initiation is a very important predictor of survival in OSCC. ${ }^{7}$ It is widely

Table II: Factors associated with recurrence at 1 year and 5 years

\begin{tabular}{|c|c|c|c|c|c|c|}
\hline \multirow[t]{2}{*}{ Factors } & \multicolumn{3}{|c|}{ Death at 1 year $(\mathrm{N}=20)$} & \multicolumn{3}{|c|}{ Death at 5 years $(\mathrm{N}=17)$} \\
\hline & Alive N (\%) & Dead N (\%) & $P$ value & Alive N (\%) & Dead N (\%) & $P$ value \\
\hline $\begin{array}{l}\text { Age, mean (standard } \\
\text { deviation) }\end{array}$ & 57.78 (14.62) & $48.50(9.19)$ & 0.398 & $58.25(17.0)$ & $57.78(10.05)$ & 0.944 \\
\hline \multicolumn{7}{|l|}{ Gender } \\
\hline Male & 12 (84.71) & $2(14.29)$ & \multirow{2}{*}{1.000} & 4(33.33) & $8(66.67)$ & \multirow{2}{*}{0.131} \\
\hline Female & $6(100.0)$ & $0(0.0)$ & & $4(80.0)$ & $1(20.0)$ & \\
\hline \multicolumn{7}{|l|}{ Race } \\
\hline Black & $8(80.0)$ & $2(20.0)$ & \multirow{3}{*}{0.579} & 3(42.86) & $4(57.14)$ & \multirow{3}{*}{0.444} \\
\hline White & $8(100.0)$ & $0(0.0)$ & & $5(62.50)$ & $3(37.50)$ & \\
\hline Coloured & $2(100.0)$ & $\mathrm{O}(0.0)$ & & $0(0.0)$ & $2(100.0)$ & \\
\hline \multicolumn{7}{|l|}{ Tobacco } \\
\hline Non-users & $2(100.0)$ & $0(0.0)$ & \multirow{2}{*}{1.000} & $1(100.0)$ & $0(0.0)$ & \multirow{2}{*}{0.471} \\
\hline Tobacco users & $16(88.89)$ & $2(11.11)$ & & $7(43.75)$ & $9(56.25)$ & \\
\hline \multicolumn{7}{|l|}{ Alcohol } \\
\hline Non-users & 8 (100.0) & $0(0.0)$ & \multirow{2}{*}{0.495} & 5 (83.33) & $1(16.67)$ & \multirow{2}{*}{0.05} \\
\hline Alcohol users & $10(83.33)$ & $2(16.67)$ & & $3(27.27)$ & 8 (72.73) & \\
\hline \multicolumn{7}{|l|}{ Stage at diagnosis } \\
\hline Stage I & $3(100.0)$ & $0(0.0)$ & \multirow{4}{*}{0.747} & $3(100.0)$ & $0(0.0)$ & \multirow{4}{*}{0.035} \\
\hline Stage II & $3(100.0)$ & $0(0.0)$ & & $2(100.0)$ & $0(0.0)$ & \\
\hline Stage III & $6(100.0)$ & $0(0.0)$ & & $2(33.33)$ & $4(66.67)$ & \\
\hline Stage IVA & $6(75.0)$ & $2(25.0)$ & & $1(16.67)$ & 5 (83.33) & \\
\hline \multicolumn{7}{|l|}{ Chemo-radiation received } \\
\hline No & $6(100.0)$ & $0(0.0)$ & \multirow{2}{*}{1.000} & $4(66.67)$ & 2 (33.33) & \multirow{2}{*}{0.335} \\
\hline Yes & $12(85.71)$ & $2(14.29)$ & & 4 (36.36) & 7 (63.64) & \\
\hline
\end{tabular}




\begin{tabular}{|c|c|c|c|c|c|c|}
\hline \multirow{2}{*}{ Factors } & \multicolumn{3}{|c|}{ Recurrence at 1 year $(\mathrm{N}=20)$} & \multicolumn{3}{|c|}{ Recurrence at 5 years $(\mathrm{N}=15)$} \\
\hline & No recurrence & Recurrence & $P$ value & No recurrence & Recurrence & $P$ value \\
\hline $\begin{array}{l}\text { Age, mean (standard } \\
\text { deviation) }\end{array}$ & $57.63(14.22)$ & 42 & - & $55.4(12.28)$ & $58(11.55)$ & 0.0702 \\
\hline \multicolumn{7}{|l|}{ Gender } \\
\hline Male & $13(92.86)$ & $1(7.14)$ & \multirow{2}{*}{1.000} & $5(50.0)$ & $5(50.0)$ & \multirow{2}{*}{0.101} \\
\hline Female & $6(100.0)$ & $\mathrm{O}(0.0)$ & & $5(100.0)$ & $0(0.0)$ & \\
\hline \multicolumn{7}{|l|}{ Race } \\
\hline Black & $9(90.0)$ & $1(10.0)$ & \multirow{3}{*}{1.000} & $3(50.0)$ & $3(50.0)$ & \multirow{3}{*}{0.336} \\
\hline White & $8(100.0)$ & $0(0.0)$ & & $6(85.71)$ & $1(14.29)$ & \\
\hline Coloured & $2(100.0)$ & $0(0.0)$ & & $1(50.0)$ & $1(50.0)$ & \\
\hline \multicolumn{7}{|l|}{ Tobacco } \\
\hline Non-users & $2(100.0)$ & $0(0.0)$ & \multirow{3}{*}{1.000} & $1(100.0)$ & $0(0.0)$ & \multirow{3}{*}{1.000} \\
\hline Tobacco users & $17(94.44)$ & $1(5.56)$ & & $9(64.29)$ & $5(35.71)$ & \\
\hline \multicolumn{5}{|l|}{ Alcohol } & & \\
\hline Non-users & $8(100.0)$ & $0(0.0)$ & \multirow{2}{*}{1.000} & $6(100.0)$ & $0(0.0)$ & \multirow{2}{*}{0.044} \\
\hline Alcohol users & $11(91.67)$ & $1(8.33)$ & & $4(44.44)$ & $5(55.56)$ & \\
\hline \multicolumn{7}{|l|}{ Stage at diagnosis } \\
\hline Stage I & $3(100.0)$ & $0(0.0)$ & \multirow{4}{*}{1.000} & $3(100.0)$ & $0(0.0)$ & \multirow{4}{*}{0.384} \\
\hline Stage ॥ & $3(100.0)$ & $0(0.0)$ & & $2(100.0)$ & $0(0.0)$ & \\
\hline Stage III & $6(100.0)$ & $0(0.0)$ & & $2(40.0)$ & $3(60.0)$ & \\
\hline Stage IVA & $7(87.50)$ & $1(12.50)$ & & $3(60.0)$ & $2(40.0)$ & \\
\hline \multicolumn{7}{|l|}{ Chemo-radiation received } \\
\hline No & $6(100.0)$ & $0(0.0)$ & \multirow{2}{*}{1.000} & $5(83.33)$ & $1(16.67)$ & \multirow{2}{*}{0.580} \\
\hline Yes & $13(92.86)$ & $1(7.14)$ & & $5(55.56)$ & $4(44.44)$ & \\
\hline
\end{tabular}

accepted that the advanced stage (Stage III and IV) cancers of the oral cavity have lower disease free and overall survival rates compared to early cancers. . $^{3,8-11}$

The prognostic implications of currently accepted pathologic features continue to be under investigation (histologic grade, lympho-vascular invasion, perineural invasion, and extracapsular spread of disease).$^{10}$ Histological features such as the grade of the lesion reflects the aggressiveness of the tumour, that, in itself has not been shown to be an independent parameter of prognosis on multivariate analysis. ${ }^{11,12}$ Other studies however have shown that the grade of tumour does affect survival. ${ }^{3,10}$ The most important histologic feature of the primary tumour is its depth of invasion, which has been shown to be directly correlated with survival rate. ${ }^{11,12}$

Depth of invasion has now been incorporated in the latest edition of the AJCC Primary tumour staging for oral cavity tumours (eighth edition) (Appendix 1). Treatment strategies are aimed to maximize locoregional tumour control and address the functional impact of a procedure on speech and swallowing.

The tumour factors that affect the choice of initial treatment of oral cancer are primary site, size (T Stage), location (anterior versus posterior), proximity to bone (mandible or maxilla), status of cervical lymph nodes and previous treatment. ${ }^{6,13,14}$

Stage IVA disease indicates moderately advanced disease but is still considered to be surgically resectable. Stage IV $\mathrm{B}$ and stage IV C disease is very advanced disease and is considered to be unresectable. ${ }^{7}$
T4a tumours that are treated surgically often result in large composite tissue defects that need to be reconstructed for functional and aesthetic outcomes. ${ }^{15,16}$ Reconstructive options include grafts, local or regional flaps as well as free tissue transfers from different sites, most commonly the leg, thigh and forearm. ${ }^{15-17}$

Primary treatment with Radiotherapy is not favoured due to the close proximity of the oral cavity sub-sites to bony structures such as the mandible and maxilla, which can lead to complications such as osteoradionecrosis of these structures. ${ }^{3,8,18}$ Thus, surgical resection has been advocated as the primary treatment for most oral cavity malignancies, with reconstruction for large defects. ${ }^{17}$ Adjuvant chemoradiation has been advocated for advanced tumours stage (III/IV) positive post-surgical margins, multiple positive neck nodes, extracapsular extension, perineural or intravascular invasion, and bone, cartilage and soft tissue invasion. 8,18

Thirty percent of patients with FOMSCC present with regional metastases and the overall 5 -year survival varies from $30-76 \% .{ }^{10,11,13,14,19}$

The primary objective of the study is to evaluate FOMSCC in our department by reporting one- and five-year overall survival rates, disease free survival and mortality rates for each stage of FOMSCC.

The secondary objective of the study is to report on demographic data of patients in the study as well as correlate these data with survival and mortality rates. These procedures use up multidisciplinary resources such ENT surgeons, plastic surgeons, maxillofacial surgeons 
Table IV: Cumulative survivor function for recurrence

\begin{tabular}{|c|c|c|c|c|c|}
\hline $\begin{array}{c}\text { Time from surgery (in } \\
\text { years) }\end{array}$ & $\begin{array}{c}\text { Total at the beginning } \\
\text { of period }\end{array}$ & $\begin{array}{c}\text { Number of } \\
\text { recurrences }\end{array}$ & Survivor Function & & $95 \% \mathrm{Cl}$ \\
\hline 1 & 19 & 1 & 0.9474 & 0.6812 & 0.9924 \\
\hline 3 & 10 & 4 & 0.7152 & 0.4425 & 0.8712 \\
\hline 5 & 8 & 0 & 0.7152 & 0.4425 & 0.8712 \\
\hline
\end{tabular}

Table IV: Cumulative survivor function for recurrence

\begin{tabular}{|c|c|c|c|c|}
\hline $\begin{array}{c}\text { Time from surgery } \\
\text { (in years) }\end{array}$ & $\begin{array}{c}\text { Total at the beginning } \\
\text { of period }\end{array}$ & $\begin{array}{c}\text { Number of } \\
\text { recurrences }\end{array}$ & $\begin{array}{c}\text { Number } \\
\text { of } \\
\text { deaths }\end{array}$ & $\mathbf{9 5 \%} \mathbf{C l}$ \\
\hline 1 & 19 & 2 & 0.9000 & 0.6560 \\
\hline 3 & 10 & 7 & 0.5385 & 0.2990 \\
\hline 5 & 8 & 0 & 0.5385 & 0.72890 \\
\hline
\end{tabular}

and prosthodontists as well as various allied disciplines. ${ }^{20}$ They are also associated with prolonged theatre times, prolonged ICU admission and prolonged hospital stays. ${ }^{20,21}$

\section{MATERIALS AND METHODS}

\section{Study design}

The study is a retrospective review of available clinical records.

\section{Study Population}

Patients diagnosed with FOMSCC who underwent oncological resection and reconstruction at $\mathrm{CMJAH}$ between January 2008 till December 2017 were included in the study.

Inclusion criteria

All patients with documented FOMSCC that underwent surgical resection.

\section{Exclusion criteria}

Patients with inadequate data in their clinical records.

Patients who could not be contacted or traced in order to determine survival.

\section{Data Collection}

Data was collected from theatre records, hospital file records, National Health Laboratory System records, ENT out-patient department records, patient/family telephonic interviews.

Recorded variables

Patient Demographics

- $\quad$ age at diagnosis

- gender

- race

Risk Factors

- $\quad$ Smoking habit

- Alcohol use

- Clinical findings

- Tumour staging at diagnosis

- Treatment

- Chemo-radiation received

Outcomes

- recurrence at 1 years

- recurrence at 5 years

- death by 1 year

- death by 5 years
Limitations of the study

This study is limited by the small sample size which could be due to the selection a single Oral SCC sub-site to reduce confounding variables.

Histopathological findings have been found to have significant prognostic markers. However, these findings were not consistently documented in the histology reports, therefore could not be accurately assessed in this study.

Poor clinical record keeping was a limitation in our study in terms of using patients clinical background such as comorbidities and overall nutritional status as predictors of survival. Prospective collection of this data will, in future, allow for a deeper analysis of the factors associated with recurrence and survival of these patients.

Ethics was granted by the Wits human and ethics research council, ethics clearance certificate number M190527.

\section{RESULTS AND DATA ANALYSIS}

All analyses were done using Stata version 15. Statistical significance was set at $5 \%$. Overall patient characteristics were tabulated. Frequencies and percentages were used to describe categorical variables; mean and standard deviation were used to describe the age. In bivariate analysis, characteristics of patients who had recurrence and those who did not were compared.

Comparisons of recurrence at one year and 5 years were made using Fisher's exact tests for categorical variables and Student's T-test for age. Similarly, characteristics of patients who died and those who survived at one year and 5 years were compared.

Time-to-event analyses were used to estimate time to recurrence and time to death. For recurrence, time was calculated from date of surgery to date of recurrence or date of death for those who died before recurrence, or date of database closure (30 November 2019) for those who did not die and did not have recurrence.

For death, time was calculated from date of surgery to date of death or date of database closure (30 November 2019) for those who did not die. We reported number of recurrences and deaths and mean follow-up time. Kaplan Meier cumulative survival curves for death and mortality were plotted and log rank tests were used to compare survivor curves. 
Adjusted and unadjusted Cox regression models were fitted to help identify predictors of mortality in patients with FOMSCC post-surgery.

\section{RESULTS}

\section{Patient demographics}

Within the study period, 20 patients were identified that were treated with resection and reconstruction for FOMSCC (Table I). The mean age at diagnosis was 56.85 years, with 70 percent of the sample being male and fifty percent being black. Amongst the sample, 90 percent of patients used tobacco and 60 percent were frequent alcohol users. The most common stage at diagnosis was stage IVA which was found in 8 patients (40 percent of the sample).

\section{Bivariate analysis - Factors associated with recurrence} There were no significant factors associated with recurrence at 1 year (Table II). At 5 years, alcohol usage was a significant predictor of recurrence $(\mathrm{P}=0.044)$.

\section{Bivariate analysis - Factors associated with death} There were no significant factors associated with death at 1 year however tumour stage at 5 years was a significant predictor ( $\mathrm{P}=0.035)$ (Table III).

\section{Survival analysis - Time to recurrence}

Out of 20 patients, five patients had recurrence. Total persontime was 72.9 person-years, with a mean follow-up time of 3.65 (SD 2.04) years per person (Table IV).

\section{Mortality - Time to death}

Out of 20 patients, nine patients died within 5 years (45\%). Total person-time was 72.9 person-years, with a mean followup time of 3.65 (SD 2.04) years per person (Table V).

\section{Predictors of mortality}

Alcohol was the only statistically significant factor associated with increased mortality (Table VI).

\section{DISCUSSION}

\section{Patient Demographics}

The data collection identified 20 patients with complete records treated for FOMSCC from 2008 to 2017. The age range of 56.85 (14.28) as well as the gender distribution was in keeping with previously reported studies where the peak age range of affected patients in the literature is $45-65.4,17$

FOMSCC has historically affected males more frequently than females however, there is an increasing incidence in females due to the rise in smoking and alcohol consumption rates in females. ${ }^{4,17}$ In this study seventy percent of patients were male and 30 percent female in keeping with the male predominance reported in the literature. ${ }^{4,17}$

In South Africa, oral SCC predominates in black males followed by Caucasian males. ${ }^{4}$ Racial demographics were the same as other studies, with black predominance, followed by white then coloured. ${ }^{4}$ The stage of tumour at presentation was more advanced in keeping with findings from other third world centres. ${ }^{11}$ This could be due to delays in appropriate referral of patients or due to delays in seeking treatment by patients due to social, educational and economic factors. Seventy percent of patients received chemo-radiation as an adjunct to surgery, this is in keeping with international guidelines. ${ }^{18}$
Factors associated with recurrence

We had a 5-year recurrence rate of $25 \%$ which is lower than that reported by Masoudi et al who had a 41\% 5-year recurrence rate. ${ }^{9}$ There was a higher number of recurrences ( 1 versus 5 ) as well as deaths (2 versus 9) from the study sample at five years compared to one year, which is in keeping with data reported by Ong et al. ${ }^{8}$ Our study showed that overall risk for recurrence increased from year 1 to 3 then stabilized. The risk of recurrence was more likely in males over females, Coloureds over Blacks and Blacks over Caucasians. Tobacco users carried a higher risk of recurrence over non-tobacco users. Those patients with stage III and stage IVA disease had a higher risk of recurrence.

An interesting observation is that patients who received adjuvant chemo-radiation had a higher risk of recurrence than those who had surgery only, however these risks were not statistically significant possibly due to the small sample size, and except for the data on chemo-radiation, these trends are in keeping with those reported in the literature..$^{22}$

Bivariate analysis showed no significant risks factors to predict recurrence at one year, however there was a significant association of recurrence $(P=0.044)$ at five years with alcohol use. Perhaps the continued use of alcohol post treatment or the oncogenic effects of synergistic alcohol and tobacco use allow for greater field mutations which, in turn, increase the risk of recurrence compared to non-alcohol users.

Factors associated with death

Our survival rate was $90 \%$ at 1 year and $55 \%$ at 5 years which is higher than literature reports by da Silva Moro et al. (42\%), le Campion et al (28\%), Santos et al. (28\%), Honorato et al. (43\%) and De Aurajo et al. (38\%), Chang et al. (48\%) and Saggi et al. (39\%).11,22,23 Patient survival decreased to nearly half from time of surgery to 3 years then stabilized.

Males were found to have a higher risk of death than females, Coloureds higher than Blacks, and Blacks higher than Caucasians, although this was not found to be statistically significant. In the literature, gender has not been shown to have a statistically significant difference in survival rates. $8,11,23$

There has been conflicting findings regarding the role of age and race regarding overall survival rates with some studies showing that they have predictive value on survival whereas others have shown that they are insignificant. ${ }^{10,11,23}$ Our findings show no statistical differences in survival based on age and race.

Tobacco chewing or smoking is one of the most prevalent risk factors identified in oral cavity SCC. There are sixty carcinogens present in tobacco smoke and at least sixteen carcinogens in unburned tobacco. ${ }^{24}$

In the literature smokers with a pack year history of over thirty years have a four-fold greater risk of getting Oral SCC. ${ }^{5}$ We found that tobacco use carried a higher risk of death over non-tobacco users although this was not statistically significant $(P=0.304)$. 
Table VI: Predictors of mortality

\begin{tabular}{|c|c|c|c|c|c|c|}
\hline \multirow[t]{2}{*}{ Factors } & \multicolumn{3}{|c|}{ Unadjusted Cox Regression Models } & \multicolumn{3}{|c|}{ Adjusted Cox Regression Model } \\
\hline & Hazard Ratios & $95 \% \mathrm{Cl}$ & $P$ Value & Hazard Ratios & $95 \% \mathrm{Cl}$ & $P$ Value \\
\hline Age & 0.99 & $0.95-1.04$ & 0.955 & 0.91 & $0.82-1.01$ & 0.096 \\
\hline \multicolumn{7}{|l|}{ Gender } \\
\hline Male & Reference & & & & & \\
\hline Female & 0.21 & $\begin{array}{l}0.02 \\
-1.69\end{array}$ & 0.142 & - & - & - \\
\hline \multicolumn{7}{|l|}{ Race } \\
\hline Black & Reference & & Reference & & & \\
\hline White & 40.7 & $0.17-3.33$ & 0.700 & 4.77 & $0.45-50.82$ & 0.196 \\
\hline Coloured & 8.71 & $1.10-69.06$ & 0.040 & 9.63 & $0.88-105.46$ & 0.064 \\
\hline \multicolumn{7}{|l|}{ Alcohol } \\
\hline Non-users & Reference & & & Reference & & \\
\hline Alcohol users & 7.60 & $0.95-61.03$ & 0.056 & 44.05 & $1.59-1221.32$ & 0.026 \\
\hline \multicolumn{7}{|l|}{ Stage at diagnosis } \\
\hline Stage I - III & Reference & & & Reference & & \\
\hline Stage IVA & 2.85 & $0.75-10.79$ & 0.122 & 3.66 & $0.59-22.71$ & 0.164 \\
\hline \multicolumn{7}{|c|}{ Chemo-radiation received } \\
\hline No & Reference & & & Reference & & \\
\hline Yes & 2.06 & $0.42-9.96$ & 0.370 & 2.23 & $0.38-12.91$ & 0.371 \\
\hline
\end{tabular}

Our study also found that alcohol use carried a statistically significant $(P=0.026)$ risk of death compared to non-alcohol users. This finding is in keeping with other studies that found alcohol usage as a significant predictor of low survival rates. ${ }^{11}$ Alcohol use is another important risk factor in the development of Oral SCC however the synergistic effect of alcohol and tobacco consumption is believed to play a greater role than either agent alone as alcohol inhibits DNA repair from cellular injury due to nitrosamines found in cigarette smoke and may also act as a solvent that facilitates the passage of carcinogens through cellular membranes.

As with recurrence there were no significant risk factors for predicting patient death at one year. At five we found a significant $(P=0.035)$ relationship between death and tumour staging. In the literature, FOMSCC has a high risk of regional lymph node metastases with an adverse impact on prognosis. Patients with lymph node metastases are staged as Stage III or IV (Appendix 1).

The literature shows that lymph node metastases reduces survival rate. ${ }^{11}$ Stage IV has been shown to have a 5 -year survival rate of $23-58 \%$, stage III $41-66 \%$, stage II $59-80 \%$ and stage I 86-94\%. Our survival rates were Stage IV 65\%, Stage III 80\%, Stage II 100\% and Stage I 100\%. ${ }^{11}$

We found that patients that had post-operative chemoradiation had a slightly lower survival rate than those who did not receive it. This was not found to be statistically significant $(\mathrm{P}=0.36)$. This finding is in keeping with findings reported by Chang et al. and Ong et al. ${ }^{8,22}$ It is however conflicting with other literature which shows that concurrent postoperative chemo-radiation improves survival rates..$^{25,26}$

\section{CONCLUSION}

Oral SCC is a multifactorial disease with a wide range of presentations, staging and prognosis. From the study performed it appears that tumour staging as well as the use of alcohol appear to be significant variable in the risk of recurrence and five-year survival of patients.

Our findings suggest earlier diagnosis, and active treatment of early-stage disease may be the best means of improving 5 -year survival rates. Efforts to improve quality of care and manage limited resources should concentrate on choosing the appropriate disease stage for surgical management, improve cancer surveillance and strengthen referral system so as to improve early detection of disease and provide social support and counselling for adjunctive habits such as alcohol and tobacco use cessation which will improve patient outcomes.

\section{SUMMARY}

- Survival rates for FOMSCC reduce with advancing stage.

- Advanced stage malignancies may require large composite resections with reconstructions. These procedures are resource intense.

- This study shows that the only significant predictors of survival was the stage at diagnosis, in keeping with international standards, and alcohol usage.

- Patients with advanced stage IVA disease should be more carefully selected for these procedures.

\section{Compliance with Ethical Standards}

\section{Conflict of interest}

The authors hereby declare that they have no conflict of interest.

\section{Ethical standards}

There was no human experimentation conducted in this study as it was a retrospective record review. 
Financial support

No financial support was required for the conduction of this study.

\section{ACKNOWLEDGEMENTS}

Department of Otorhinolaryngology, University of the Witwatersrand.

\section{References}

1. Ferlay J, Soerjomataram I EM et al.: Cancer Incidence and Mortality Worldwide: Sources, Methods and major patterns in GLOBOCAN 2012. Int J Cancer 136:359386, 2015.

2. Shah JP, Patel SG, Singh B: Head and Neck Surgery and Oncology: Oral Cavity. 4th ed. Philadelphia, Mosby, 2012, pp 232-290.

3. Farhood, Z, Simpson M, Ward GM, Walker RJ, Osazuwa-Peters N: Does Anatomic Subsite Influence Oral Cavity Cancer Mortality? A SEER Database Analysis. Laryngoscope 129(6):1400-1406, 2019.

4. Abram MH. The Incidence of Oral and Oropharyngeal Cancer in South Africa for the five-year period 19972001: Master's Dissertation [Internet]. 2013;1-54. Available from: https://repository.up.ac.za/bitstream/ handle/2263/24655/dissertation.pdf sequence=1

5. Wein RO: Malignant Neoplasms of the Oral Cavity. In: PW F, editor. Cummings Otolaryngology Head and Neck Surgery. 6th ed. Philadelphia, Elsevier Saunders; 2015, pp. 1359-87.

6. Shah JP, Gil Z: Current Concepts in Management of Oral Cancer Surgery. Oral Oncol. 45(4-5):394-401, 2009.

7. Deschler DG, Moore MG, Smith RV: Quick Reference Guide to TNM Staging of Head and Neck Cancer and Neck Dissection Classification. American Academy of Otolaryngology-Head and Neck Surgery Foundation. [Internet]. 4th ed. 2014; 1-34. Available from: https:// www.entnet.org/sites/default/files/ChapterTwoFINAL. pdf

8. Ong TK, Murphy C, Smith AB, Kanatas AN, Mitchell DA: Survival After Surgery for Oral Cancer: a 30year Experience. $\mathrm{Br} J$ Oral Maxillofac Surg [Internet]. 2017;55(9):911-6. Available from: http://dx.doi. org/10.1016/j.bjoms.2017.08.362

9. Masoudi S, Montazeri SA, Pourdanesh F, Biglarian A, Kazemi M, Rahgozar M: A New Approach to Survival Analysis of Head and Neck Squamous Cell Carcinoma. Arch Iran Med 20(8):503-10, 2017.

10. Saggi S, Badran KW, Han AY, Kuan EC, St. John MA. Clinicopathologic Characteristics and Survival Outcomes in Floor of Mouth Squamous Cell Carcinoma: A Population-Based Study. Otolaryngol Head Neck Surg 159(1):51-8, 2018.

11. Le Campion ACOV, Ribeiro CMB, Luiz RR, Da Silva Júnior FF, Barros HCS, Dos Santos KDCB, et al.: Low Survival Rates of Oral and Oropharyngeal Squamous Cell Carcinoma. Int J Dent 2017:5815493, 2017.

12. Spiro RH, Huvos AG, Wong GY, Spiro JD, Gnecco CA, Strong EW: Predictive Value of Tumor Thickness in Squamous Carcinoma Confined to the Tongue and Floor of the Mouth. Am J Surg 152(4):345-50, 1986.

13. Sessions DG, Spector GJ, Lenox J, Parriott S, Haughey $B$, Chao $C$ et al.: Analysis of Treatment Results for Floor-
of-Mouth Cancer. Laryngoscope 110:1764-72, 2000.

14. Mashberg A MH. Anatomical Site and Size of 222 Early Asymptomatic Oral Squamous Cell Carcinomas: A Continuing Prospective Study of Oral Cancer. Cancer 37:2149-57, 1976.

15. Oxford Cancer Intelligence Unit: Major Surgical Resections in England: head and neck cancers. [Internet]. 2011; 1-40. Available from: file:///C:/Users/ patelp/Downloads/Major_surgical_resections_in_ England_head_and_neck_cancers_f\%20(1).pdf

16. Salvatori P, Paradisi S, Calabrese L, Zani A, Cantù G, Cappiello J, et al.: Patients' Survival after Free Flap Reconstructive Surgery of Head and Neck Squamous Cell Carcinoma: A Retrospective Multicentre Study. Acta Otorhinolaryngol Ital [Internet]. 2014;34(2):99104. Available from: https://pubmed.ncbi.nlm.nih. gov/24843219/

17. Sarafoleanu C, Vuzitas A, Manea C: Difficulties in the surgical management of head and neck cancer patient. Rom J Rhinol 7(27):153-61, 2017.

18. Roland NJ: Head and Neck Cancer: Multidisciplinary Management Guidelines. [Internet]. 4th ed. 2011. Available from: http://www.entuk.org/

19. Hicks WL, Loree TR, Garcia RI, Maamoun S, Marshall D, Orner JB et al.: Squamous Cell Carcinoma of the Floor of Mouth: A 20-year Review. Head Neck19(5):400-5, 1997.

20. Baujat B, Altabaa K, Meyers M, Wagner I, Leclerc C, Chabolle F: Medicoeconomic study of microsurgical head and neck reconstructions. Eur Ann Otorhinolaryngol Head Neck Diseases [Internet]. 2011;128(3):121-6. Available from: http://dx.doi.org/10.1016/j.anorl.2011.01.002

21. Jayakar R, Choi J, MacKinnon C, Tan S: The Cost of Major Head and Neck Cancer Surgery. N Z Med J 130(1455):111-9, 2017.

22. Chang El, Peirong Y, Skoracki RJ, Liu J, Hanasono MM: Comprehensive Analysis of Functional Outcomes and Survival After Microvascular Reconstruction of Glossectomy Defects. Ann Surg Oncol 22(9):3061-9, 2015.

23. Moro J da S, Maroneze MC, Ardenghi TM, Barin LM, Danesi CC. Oral and oropharyngeal cancer: epidemiology and survival analysis. Einstein (Sao Paulo) 16(2):eAO4248, 2018.

24. Centers for Disease Control and Prevention (US). How Tobacco Smoke Causes Disease: The Biology and Behavioral Basis for Smoking-Attributable Disease. [Internet]. 2010. Available from: https://www.ncbi.nlm. nih.gov/books/NBK53010/

25. Spiotto MT, Jefferson $G$, Wenig B, Markiewicz $M$, Weichselbaum RR, Koshy M: Differences in Survival with Surgery and Postoperative Radiotherapy compared with Definitive Chemoradiotherapy for Oral Cavity Cancer: A National Cancer Database Analysis. JAMA Otolaryngol Head Neck Surg 143(7):691-699, 2017.

26. Nandakumar A, Rath GK, Kataki CA, Bapsy P, Gupta PC: Survival in Head and Neck Cancers - Results of A Multi-Institution Study: Asian Pac J Cancer. Prev 17(4):1745-54, 2016. 


\section{APPENDIX 1}

American Joint Committee on Cancer (AJCC) Tumour Staging 8th Edition by Site: ORAL CAVITY

\section{PRIMARY TUMOUR (T)}

TX Primary tumour cannot be assessed

$\mathrm{T} \quad$ is Carcinoma in situ

T1 Tumour $\leq 2 \mathrm{~cm}, \leq 5 \mathrm{~mm}$ depth of invasion (DOI)

T2 Tumour $\leq 2 \mathrm{~cm}$, DOI $>5 \mathrm{~mm}$ and $\leq 10 \mathrm{~mm}$; or tumour $\mathrm{cm}$ but $\leq 4 \mathrm{~cm}$, and $\mathrm{DOI} \leq 10 \mathrm{~mm}$

T3 Tumour $>4 \mathrm{~cm}$; or any tumour with $\mathrm{DOI}>10 \mathrm{~mm}$ but $\leq 20 \mathrm{~mm}$

T4 Moderately advanced or very advanced local disease

T4a Moderately advanced local disease:

Tumour invades adjacent structures (e.g. through cortical bone of the mandible or maxilla, or involves maxillary sinus or skin of the face) or extensive tumour with bilateral tongue involvement and/or DOI > $20 \mathrm{~mm}$

Note: Superficial erosion of bone/tooth socket (alone) by a gingival primary is not sufficient to classify a tumour as T4. T4b Very advanced local disease:

Tumour invades masticator space, pterygoid plates, or skull base and/or encases internal carotid artery

\section{REGIONAL LYMPH NODES (N)}

NX Regional lymph nodes cannot be assessed NO No regional nodes metastasis

N1 Metastasis in a single ipsilateral lymph node, $3 \mathrm{~cm}$ or less in greatest dimension

$\mathrm{N} 2 \mathrm{a}$ Metastasis in a single ipsilateral lymph node, more than $3 \mathrm{~cm}$ but not more than $6 \mathrm{~cm}$ in greatest dimension

\begin{tabular}{|c|c|c|c|}
\hline \multicolumn{4}{|c|}{ TNM Staging, Oral Cavity } \\
\hline Stage 0 & Tis & NO & MO \\
\hline Stage I & $\mathrm{T} 1$ & NO & MO \\
\hline Stage II & T2 & NO & MO \\
\hline \multirow[t]{4}{*}{ Stage III } & T3 & NO & MO \\
\hline & $\mathrm{T} 1$ & N1 & MO \\
\hline & T2 & N1 & MO \\
\hline & Тз & N1 & Mo \\
\hline \multirow[t]{6}{*}{ Stage IVA } & $\mathrm{T} 4 \mathrm{a}$ & No & MO \\
\hline & $\mathrm{T} 4 \mathrm{a}$ & N1 & MO \\
\hline & $\mathrm{T} 1$ & N2 & MO \\
\hline & T2 & N2 & MO \\
\hline & Т3 & N2 & MO \\
\hline & $\mathrm{T} 4 \mathrm{a}$ & N2 & MO \\
\hline \multirow[t]{2}{*}{ Stage IVB } & Any $T$ & N3 & M \\
\hline & $\mathrm{T} 4 \mathrm{~b}$ & Any $\mathrm{N}$ & MO \\
\hline Stage IVC & Any $T$ & Any N & M1 \\
\hline
\end{tabular}

N2b Metastasis in multiple ipsilateral lymph nodes, none more than $6 \mathrm{~cm}$ in greatest dimension

N2c Metastasis in bilateral or contralateral lymph nodes, none more than $6 \mathrm{~cm}$ in greatest dimension

$\mathrm{N} 3 a$ Metastasis in a lymph node more than $6 \mathrm{~cm}$ in greatest dimension

N3b Metastases in any node with clinically overt extra nodal extension

\section{DISTANT METASTASIS (M)}

MX Distant metastasis cannot be assessed

MO No distant metastasis

M1 Distant metastasis

\section{YOU ARE ONE PHONE CALL AWAY FROM A SOLUTION!}

\section{SPECHAL OFFER. (OOT 21 TOMARRH 22)}

\section{LEET US DEAL WITH YOURA)}

\section{*Importing and Exporting Anguish!}

- Procurement of goods for business use

- Freight Forwarding (By air and road)/Logistics

- Customs Clearing

Look no more - we offer best services for all your medical and dental consumables and equipment
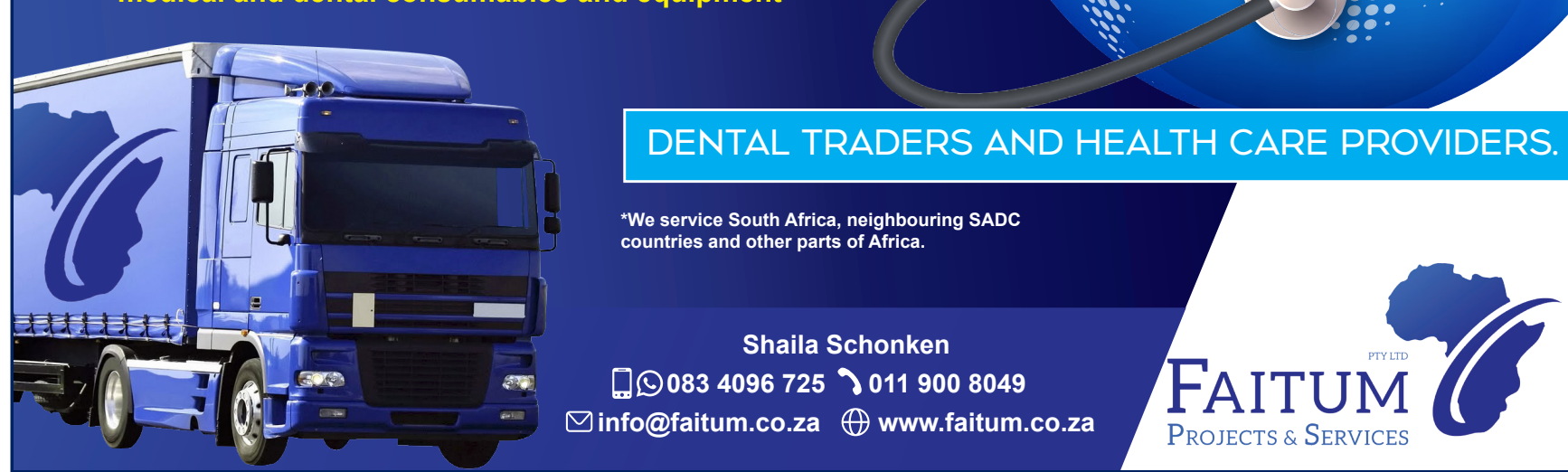

DENTAL TRADERS AND HEALTH CARE PROVIDERS.

*We service South Africa, neighbouring SADC countries and other parts of Africa. 